\title{
A NEW SUBCLASS OF HARMONIC UNIVALENT FUNCTIONS ASSOCIATED WITH FRACTIONAL CALCULUS OPERATOR
}

\author{
SAURABH PORWAL
}

Abstract. The purpose of the present paper is to study a new subclass of harmonic univalent functions associated with fractional calculus operator. We obtain coefficient conditions, distortion bounds and extreme points for this class and discuss a class preserving integral operator. We also show that the class studied in this paper is closed under convolution and convex combination. The results obtained for the class reduce to the corresponding results for several known classes in the literature are briefly indicated.

Mathematics subject classification (2010): 30C45, 30C50.

Keywords and phrases: Harmonic, analytic, univalent, extreme points, fractional calculus.

\section{REFERENCES}

[1] O. P. Ahuja, Planar harmonic univalent and related mappings, J. Inequal. Pure Appl. Math., 6 (4) (2005), Art. 122, 1-18.

[2] J. Clunie And T. Sheil-Small, Harmonic univalent functions, Ann. Acad. Sci. Fenn. Series A. I. Math., 9 (1984), 3-25.

[3] K. K. Dixit AND A. L. PATHAK, A new class of analytic functions with positive coefficients, Indian J. Pure Appl. Math., 34 (2), (2003), 209-218.

[4] K. K. Dixit And A. L. PathaK, On a new class of close-to-convex functions with positive coefficients, Bull. Cal. Math. Soc., 97 (6), (2005), 531-542.

[5] K. K. Dixit and Saurabh Porwal, An application of fractional calculus to harmonic univalent functions, Bull. Cal. Math. Soc., 102 (4) (2010), 343-352.

[6] P. Duren, Harmonic mappings in the plane, Cambridge University Press, Cambridge, 2004.

[7] S. OWA, On the distortion theorem I, Kyungpook Math. J., 18 (1978), 53-59.

[8] S. OWA AND H. M. SRIVASTAVA, Univalent and starlike generalized hypergeometric functions, Canad. J. Math., 39 (1987), 1057-1077.

[9] S. Ponnus Amy AND A. Rasila, Planar harmonic and quasiconformal mappings, RMS Mathematics Newsletter, 17 (3) (2007), 85-101.

[10] Saurabh Porwal And K. K. Dixit, New subclasses of harmonic starlike and convex functions, Kyungpook Math. J., 53 (2013), 467-478.

[11] Saurabh Porwal And M. V. Singh, Convolution on a certain class of harmonic univalent functions, J. Indian Math. Soc., 82 (1-2) (2015), 117-127.

[12] H. M. SRivastava And S. OWA, An application of the fractional derivative, Math. Japon., 29 (1984), 383-389.

[13] B. A. URAlEgaddi, M. D. GANigi And S. M. SARANGi, Univalent functions with positive coefficients, Tamkang J. Math., 25 (1994), 225-230.

[14] B. A. Uralegaddi, M. D. Ganigi And S. M. Sarangi, Close-to-convex functions with positive coefficients, Studia Univ. Babes-Balyai, Mathematica, XL4, (1995), 25-31. 